\title{
Erratum to: Reply to Comment on "HydrogeoSieveXL: an Excel-based tool to estimate hydraulic conductivity from grain-size analysis": technical note published in Hydrogeology Journal (2015) 23: 837-844, by J. F. Devlin
}

\section{J. F. Devlin ${ }^{1}$}

Published online: 9 January 2017

(C) Springer-Verlag Berlin Heidelberg 2017

Erratum to: Hydrogeology Journal (2016)

DOI 10.1007/s10040-016-1510-z

The correct version of Figure $\underline{1}$ is shown here. Note Figure 1a now correctly depicts the Borden aquifer sand.

The online version of the original article can be found at http://dx.doi. org/10.1007/s10040-016-1510-z.

\footnotetext{
J. F. Devlin

jfdevlin@ku.edu

1 Department of Geology, University of Kansas, Lindley Hall rm 120, 1475, Jayhawk Blvd., Lawrence, KS 66049, USA
} 

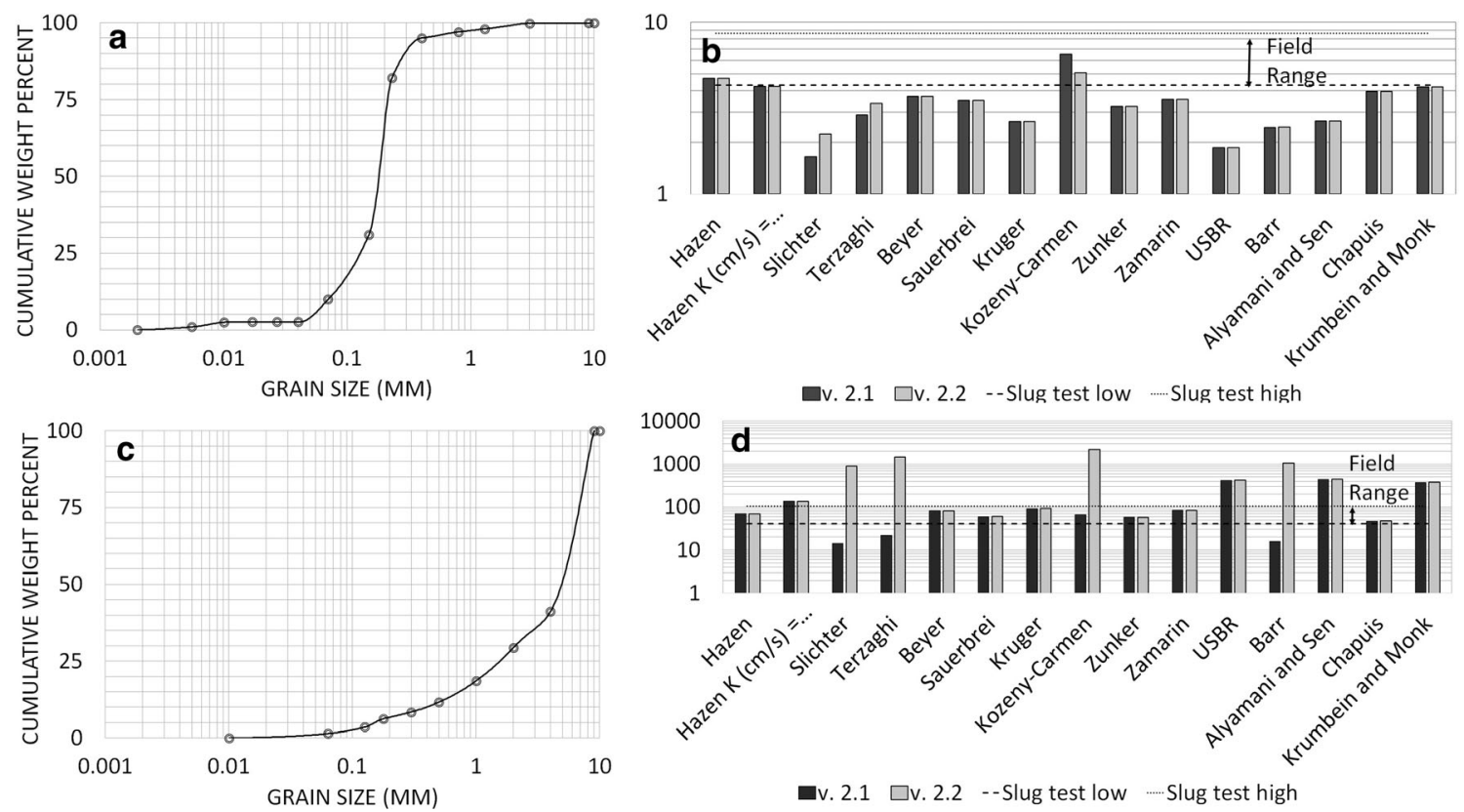

Fig. 1 a Grain-size curve for the well-sorted Borden aquifer sand as reported by Thomson et al. (2007). b Hydraulic conductivity estimates from the 15 HydrogeoSieveXL equations from v. 2.1 and v. 2.2 (invoking the $d_{\mathrm{m}}$ and $n_{\mathrm{e}}$ recommended values in the Comment) compared to the field measured values of hydraulic conductivity. c Grain-size curve for the weakly sorted aquifer at Woodstock, Ontario, as reported by Schillig

(2012). d Hydraulic conductivity estimates from the 15 HydrogeoSieveXL equations from v. 2.1 and v. 2.2 (invoking the $d_{\mathrm{m}}$ and $n_{\mathrm{e}}$ recommended values in the Comment) compared to the field estimated values back-calculated from tracer tests, hydraulic head measurements and Darcy's Law (Critchley et al. 2014) 